\title{
Cleft Palate
}

Tomasz R. Kosowski, MD ${ }^{1}$ William M. Weathers, MD² Erik M. Wolfswinkel, BS ${ }^{2} \quad$ Emily B. Ridgway, MD ${ }^{1}$

${ }^{1}$ Division of Plastic Surgery, Department of Surgery, Dartmouth Hitchcock Medical Center, Lebanon, New Hampshire

2 Division of Plastic Surgery, Department of Surgery, Baylor College of Medicine, Houston, Texas
Address for correspondence and reprint requests Emily B. Ridgway, MD, Division of Plastic Surgery, Dartmouth Hitchcock Medical Center, One Medical Center, Lebanon, NH, 03756

(e-mail: Emily.b.ridgway@hitchcock.org).

Semin Plast Surg 2012;26:164-169.
Abstract
Keywords
- congenital
- cleft palate
- velopharyngeal insufficiency

Our understanding of cleft palates has come a long way over the last few decades. A better understanding of the long-term consequences of a cleft palate and its effect on speech development challenges surgeons to not only effectively repair the cleft, but to also restore function of the palate for adequate speech. Coordination with speech pathologists is integral for effective management of cleft palate patients, particularly as children begin to develop language. In this article, the authors review and summarize the various challenges and goals of cleft palate management.
Cleft lip and palate are the most common congenital craniofacial anomalies evaluated by a plastic surgeon. These anomalies are being detected earlier, often with fetal ultrasound and magnetic resonance imaging (MRI), thus preparing parents with a prenatal diagnosis. An expecting mother is often seen by a plastic surgeon prior to the delivery of her infant. Successful treatment depends on accurate diagnostic evaluations, surgical experience, knowledge of three-dimensional (3D) normal and abnormal anatomy, meticulous postoperative and longitudinal care, and collaboration with a multidisciplinary team. The consequences of an orofacial cleft are not limited to cosmetic deformities, but also dental abnormalities, speech distortion, disorganized swallowing, and growth difficulties. In this article, we will review the epidemiology, embryology, and anatomy of the cleft palate; present a classification schema; review clinical manifestations and treatment options; as well as outcomes with surgical and nonsurgical care.

\section{Epidemiology}

Cleft palate represents the third most frequently occurring congenital deformity after clubfoot and cleft lip. Among the cleft lip and palate population, the most common diagnosis is unilateral cleft lip and palate (46\%), followed by isolated cleft palate (33\%). Cleft palates affect 1:2,000 live births worldwide regardless of race. ${ }^{1}$ This is in contrast to cleft lips, which show racial variability with the highest incidence in Asian and Native Americans (1:450 live births) and the lowest incidence in African Americans (1:2,000 live births). Isolated cleft palate occurs more in females (57\%) than in males (43\%). Gender differences may be related to differences in timing of embryologic development. ${ }^{2}$

\section{Genetics}

Familial inheritance does occur in cleft palate, but classic Mendelian inheritance is rare. Multifactorial inheritance is much more common, making the underlying genetic traits that predispose to clefting difficult to discern. Approximately $50 \%$ of isolated cleft palates are associated with a malformation syndrome, compared with less than $15 \%$ of combined cleft lip and palate patients. ${ }^{3}$ The most common syndrome associated with isolated cleft palate is velocardiofacial syndrome (VCFS). This syndrome is a result of microdeletions of chromosome 22q. In addition, abnormalities of chromosomes $1,2,4,6,11,14,17$, and 19 are associated with palatal clefting, many with unnamed syndromes. ${ }^{4}$

Gestational exposures to alcohol, cigarette smoking, steroids, rubella, anticonvulsants (phenobarbital and phenytoin), retinoids, and hypoxia have all been associated with cleft palate. ${ }^{5,6}$ Advanced paternal age, parental folate deficiency, and hypoxia are associated with an increased risk of cleft lip or palate. $^{7}$

Counseling new or expecting parents with a personal history of clefting regarding risk rates of cleft palate in future offspring should be part of every initial consultation. The risk of an affected parent having a child with a cleft palate is $7 \%$. If
Issue Theme Pediatric Plastic Surgery-Clefts; Guest Editor, Edward P. Buchanan, MD.
Copyright $\odot 2012$ by Thieme Medical Publishers, Inc., 333 Seventh Avenue, New York, NY 10001, USA. Tel: +1(212) 584-4662.
DOI http://dx.doi.org/ 10.1055/s-0033-1333883. ISSN 1535-2188. 
one sibling has a palatal cleft with no parental clefts, then future siblings have a $2 \%$ risk of developing a cleft. That risk increases to $17 \%$ if there is one affected sibling and a parent with a cleft. ${ }^{8}$

\section{Anatomy}

The primary palate includes the alveolar arch. The secondary palate includes the hard and soft palate. The hard palate is formed by the palatine processes of the maxillae and by the horizontal lamina of the palatine bones. It is covered by oral and nasal mucosa. The chief blood supply is from the greater palatine artery, which originates from the internal maxillary artery (internal carotid system) and passes through the greater palatine foramen. Sensation is supplied by the anterior palatine and nasopalatine nerves. ${ }^{9}$

The soft palate (velum) is a fibromuscular shelf made up of five muscles attached as a sling to the posterior portion of the hard palate. It functions to elevate the nasopharynx, effectively closing the communication from the nasopharynx to the oropharynx. It also serves as the anterior wall of the velopharyngeal port, a sphincter mechanism of which the posterior and lateral walls consist of the superior pharyngeal constrictor. This muscular valve aids in breathing, blowing, swallowing, and phonation. The velum consists of the tensor veli palatini muscle $(\mathrm{CN} \mathrm{V})$, which tenses and depresses the soft palate and opens the eustachian tube; the levator veli palatini muscle (CNs X, IX), which elevates the palate; the uvulus muscle (CN IX, X), which pulls the uvula cranially and anteriorly; and the glossopalatine (CNs IX, X) and the palatopharyngeus (CNs IX, X) muscles, which draw the palate inferiorly and constrict the pharynx. ${ }^{10}$

A cleft palate spans many degrees of severity and can include the soft palate, hard palate, and alveolus. Clefting disrupts the palatal sling secondary to abnormal insertions of the soft palate muscles into the posterior margin of the remaining bony palate rather than the midline raphe. As a result, the affected individual loses velopharyngeal competence, which may lead to potential speech distortion, such as nasal air emission and hypernasality. ${ }^{11}$ Eustachian tube control is often lost as well, manifesting as recurrent otitis. ${ }^{12}$

\section{Embryology}

The neural crest theory of development holds that neural crest cells, specialized embryonic cells that give rise to various connective and neural tissues of the skull and face, migrate at different rates to form the preliminary palate. If the migration fails to occur, or if there is an absence or inadequacy of related cells, clefts and other facial abnormalities may result. ${ }^{13}$ In general, children with clefts have a deficiency of tissue, not merely a displacement of normal tissue. ${ }^{14}$

The primary palate begins to form during the fifth week with the appearance of the frontonasal process, an area of neural crest cells anterior to the developing brain. The lateral aspect of the frontonasal process will thicken to form the nasal placode. This eventually invaginates to form the nasal pit, which is the precursor to the nostril. The area medial and lateral to the nasal pits are known as the medial and lateral nasal prominences, respectively. During the fifth and sixth weeks of gestation, the medial nasal prominence will fuse with the maxillary prominence, an area of specialized mesenchymal tissue along the anterior mandibular arches. Fusion of the primary palate is complete by the sixth week. The nasal tip, columella, and philtrum are derived from the medial nasal prominence. The lateral upper lip forms from the maxillary prominence. The lateral nasal prominence will form the nasal alae. ${ }^{15}$

Cleft lip results from a failure to maintain an epithelial bridge due to lack of mesodermal delivery and proliferation from the maxillary and nasal processes. Isolated clefts of the primary palate occur anterior to the incisive foramen. At no time during normal development of the lip and primary palate does a cleft exist. This is in contrast to the secondary palate, which requires midline fusion of lateralized analogous tissues. This process begins in the sixth week with the outgrowth of the palatine shelves from the maxillary prominences. Although they initially grow vertically on each side of the tongue, the palatine shelves will change orientation and begin to grow and fuse in the horizontal direction with the anteroinferior dissent of the tongue. Fusion proceeds in a posterior direction from the incisive foramen with the fusion of the maxilla and vomer to form the bony hard palate completed by the ninth week of gestation. This process continues into the $12^{\text {th }}$ week when the soft tissues posterior to the hard palate also meet to form the soft palate. Lack of fusion of the palatal shelves results in clefts of the secondary palate. ${ }^{15,16}$

The female palate is known to close one week later than the male palate, an observation that may explain why isolated clefts are more common in females than males. As noted above, cleft lip with cleft palate is the most common presentation of orofacial clefting. Cleft lip occurs at an earlier age in embryologic development; this lip discontinuity results in obstruction of tongue migration that frequently interferes with horizontal alignment and fusion of the palatal shelves. Thus, cleft lip increases the probability of a cleft palate developing. A specific variant of cleft palate, independent of lip formation, results from the failure of tongue dissent due to obstruction from an underdeveloped maxilla. This is known as Pierre Robin sequence, and manifests as a large U-shaped palatal cleft. ${ }^{17}$

\section{Cleft Classification}

A cleft palate may be either unilateral or bilateral and is either complete or incomplete (-Fig. 1). ${ }^{15}$ A complete cleft of the entire palate involves the length of the primary and secondary palate. An incomplete cleft involves only the secondary palate.

A submucous cleft palate is a form of cleft palate that may grossly appear to be structurally intact, but there are both muscular and bony deficits. The defects include a bony notch in the hard palate, a bluish line at the midline of the soft palate (zona pellucida) indicating a separation of the submucosal palatal musculature, and a bifid uvula (-Fig. 2). The bony notch can be seen or felt where normally the posterior nasal spine is found along the posterior border of the hard palate. ${ }^{18}$ 


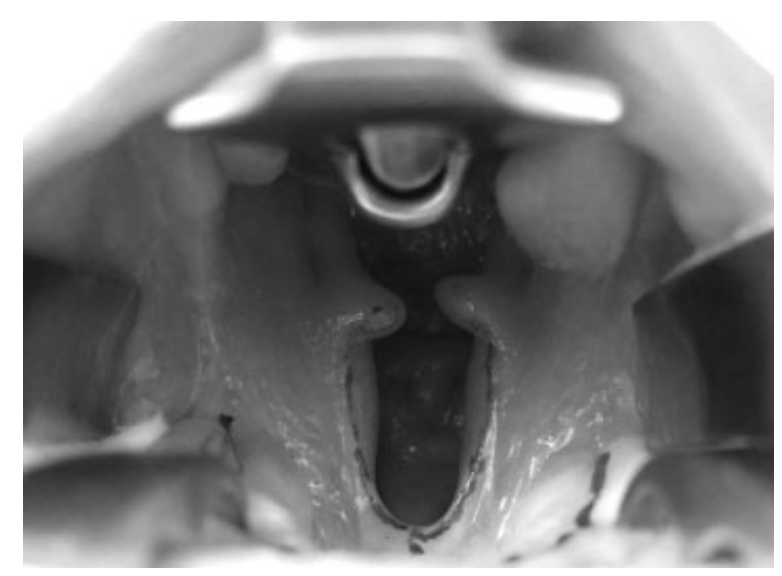

Fig. 1 Midline cleft involving the soft palate and the posterior portion of the hard palate, otherwise known as a Veau class II.

The submucous cleft of the hard palate is not functionally significant. However, the muscular deficit found in the soft palate often is functionally significant. ${ }^{19}$ The levator muscles in these cases are often found to be inserted into the hard palate instead of interdigitating to form the normal levator sling. This condition foreshortens the functional soft palate and creates further complexity, which may contribute to velopharyngeal incompetence.

The Veau System classifies orofacial clefting into four classes by whether the secondary and/or primary palates are affected and by laterality. ${ }^{20}$

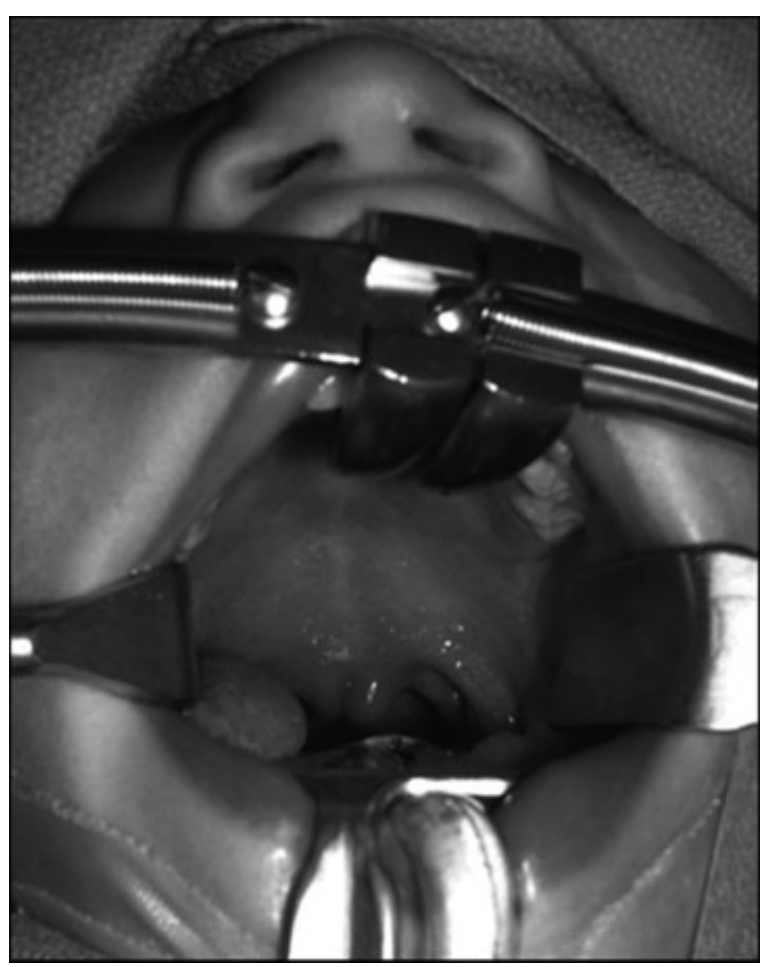

Fig. 2 Submucous cleft with zona pellucida and a bifid uvula. Palpation along the midline would reveal a notch at the hard palate.
Veau Class I: Incomplete cleft, soft palate only (no unilateral/bilateral designation)

Veau Class II: Hard and soft palate, secondary palate only (no unilateral/bilateral designation)

Veau Class III: Complete unilateral cleft including lip (primary and secondary palates)

Veau Class IV: Complete bilateral cleft

\section{Clinical Manifestations}

One of the first manifestations associated with cleft palate is difficulty with feeding. ${ }^{21}$ Breast feeding can be challenging and specialized feeding strategies including the use of a Habermann feeder, Montgomery nipple, bulb syringe, or pigeon feeder are frequently required. The infant should be fed in a slightly upright position. Aerophagia is a problem in these infants and requires more frequent burping and slower feeding. In rare cases, a nasogastric tube or surgical gastric tube may be necessary as the infant learns to feed from a bottle.

Cleft palate repair is designed to allow separation of the nasal and oropharynx. If unsuccessful or if left untreated, velopharyngeal insufficiency (VPI) results and speech distortion develops as the child grows. ${ }^{22}$ The inability to generate intraoral breath pressure due to nasal air emission in cleft palate patients frequently manifests as articulation difficulties, particularly consonant weakness, and unintelligible speech. The most common articulation error in velopharyngeal insufficiency is the consonant $/ \mathrm{s} /$. As the incompetence increases, other sibilants and fricatives (|f/, /v/, |th/, /sh/, |z/, $|\mathrm{s} /,| \mathrm{zh} /)$ become involved. Still greater incompetence in this critical valve will lead to reduced intraoral pressure in association with plosives. ${ }^{23}$

Sounds most frequently misarticulated include /s/ (63\%), $\mid \mathrm{z} /(61 \%), / \mathrm{d} /(48 \%), / \mathrm{ch} /(44 \%), / \mathrm{p} /(11 \%)$, and /b/ (9\%).

Sound substitutions are characteristic of young children who are still in the process of learning speech. Speakers with cleft palates substitute a nasal consonant for a consonant that requires intraoral pressure (for example, substituting $/ \mathrm{m} /$ for $/ \mathrm{b} /$ ). In some instances, this response is regarded as a nasally distorted $/ \mathrm{b} /$ rather than the substitution of $/ \mathrm{m} /$. Omissions are another form of speech error in which final consonants are deleted as a means of avoiding nasal emission.

Some speakers with VPI seem to accept their loss of intraoral pressure and continue to articulate accurately. These speakers may have weak consonants and audible escape, but placement is accurate, and intelligibility may be only slightly impaired. Others attempt to compensate for their valving deficits by seeking new approaches to consonant articulation. These individuals produce a sibilant-like consonant pharyngeally rather than in the anterior palate. They adopt gross articulation errors, which are referred to as pharyngeal fricative and glottal stops. Patients substitute a glottal stop (whispered cough) for stop-plosives (/p/, /t/, /k/, /b/, /d/, /g/). Glottal stops are made by closing the glottis, building up pressure within the trachea, and then suddenly reopening the glottis to release a transient puff of air. Patients also substitute pharyngeal fricatives for fricative consonants. Pharyngeal 
fricatives are produced by positioning the tongue close to the back wall of the throat or by decreasing the side to side diameter of the throat by moving the walls of the pharynx inward. Air is then forced through the constricted pharyngeal airway to produce a turbulent sound. These compensations are rarely accompanied by nasal escape because that critical nasopharyngeal valve is bypassed.

Perhaps the most known speech distortion attributed to cleft palate is hypernasality-the perception of excessive nasal resonance during the production of vowels. ${ }^{24}$ This abnormality results from inadequate closure of the velopharyngeal valve and increased oral cavity constriction, which forces more sound waves into the nasal cavity. This constriction may be the result of restricting mouth opening during speech, posterior or superior positioning of the dorsum of the tongue during articulation of some sounds, or abnormal positioning or tension of the pharynx. Some patients attempt to control hypernasality by tightening both the respiratory muscles and laryngeal muscles to control air flow before it reaches the crucial velopharyngeal valve. Often, these patients are noted to have hoarseness, harshness, and vocal nodules.

Other vocal distortions seen include reduced loudness, monotone quality, and occasionally a strangled voice quality. Aerodynamic and acoustical factors contribute to the reduced loudness rather than reduced self-confidence or self-consciousness. Often accompanying the soft-voice syndrome is the monotonous voice with little pitch variation. Patients with this problem are often unable to demonstrate pitch variations of more than three or four tones. Strangled voice quality appears to be associated with an attempt to be nonnasal in the presence of VPI. Phonation is associated with extreme tension in the abdominal, diaphragmatic, thoracic, laryngeal, and supraglottal muscles. It appears as if the person is trying to hold his breath and talk at the same time.

Hearing disorders are prevalent among individuals with orofacial clefts. These disorders are a result of chronic otitis media with effusion due to eustachian tube dysfunction. The tensor veli palatini muscle that normally functions to open the eustachian tube fails to do so causing pressure and fluid build-up in the middle ear with subsequent infections, inflammation, and scarring. ${ }^{25}$ These patients often suffer from conductive hearing loss as a result. Some form of hearing disorder is present in all infants with unrepaired palatal clefts before the age of 2 years.

\section{Treatment}

A multidisciplinary team is essential to manage the many facets affected by orofacial clefting. The reconstructive surgeon works in cooperation with otolaryngologists, dentists and orthodontists, speech pathologists, audiologists, geneticists, psychiatrists, maxillofacial surgeons, social workers, and prosthodontists. ${ }^{26}$ Treatment of cleft palate has evolved. The techniques of cleft palate repair that are practiced today are the result of principles learned through many years of modifications. The challenge of modern palatoplasty is no longer simply successful closure of the cleft palate. Enabling optimal speech without compromising maxillofacial growth is the goal of the modern craniofacial surgeon. ${ }^{27}$

Nonsurgical treatment of the cleft palate is attempted with prosthodontic devices designed to correct velopharyngeal incompetence. Indications for use of prosthodontic devices are rare and largely of historical interest. Candidates who may benefit from prosthodontic devices are those who do not want or are too high risk for surgery, those in whom surgery has failed, or patients who would benefit from better alignment of the maxillary segments prior to definitive surgery. ${ }^{28}$ The major disadvantage is that the prosthesis must be readjusted every 2 weeks until growth is finished. Additionally, the device may be irritating to the fragile mucosal surface, difficult to clean, and require cooperation on the child's behalf. Obturation is practical beginning at ages 3 to 4 years. The principle advantage is achieving as high or a higher rate of velopharyngeal competence than with surgery while avoiding potential surgical complications, such as restricted maxillary growth.

Cleft patients are capable of normal facial skeleton development, but corrective surgical procedures are known to impair maxillary growth and may lead to midface retrusion. ${ }^{29}$ The primary goals of palatoplasty are to restore velopharyngeal function and to ensure normal speech development, while avoiding palatal fistulas and maxillary growth restriction. Fewer maxillary growth complications are seen with procedures that produce less tension on the palate, and as a result produce less scar tissue on the denuded palate.

Optimal timing of cleft palate repair must take into account other medical conditions and speech development. Early repair has been shown to benefit speech development, but may inhibit facial growth to a greater extent as transverse facial growth is not complete until 5 years of age. In the past, surgery on the palate was often delayed until maxillary growth was completed or when deciduous molars achieved proper occlusion. Recently, speech outcomes have taken precedence and as a result, most experts repair cleft palates beginning at 10 months of age. ${ }^{27,30}$ Some advocate waiting until 2 years of age to operate on large cleft palates. Surgery on isolated soft palate clefts has been advocated as early as 3 months of age.

The most common surgical techniques for repair of the soft palate are the Furlow double-opposing Z-plasty (-Fig. 3) and the intravelar veloplasty. The bony palate is often repaired using the Von Langenbeck palatoplasty, the Veau-WardillKilner palatoplasty, or a Bardach two-flap palatoplasty. Vomer flaps are used in conjunction with the above hard palate repairs to repair the nasal mucosa. ${ }^{31,32}$

\section{Outcomes}

The most common complications following surgical repair of cleft palate include palatal fistula, persistent velopharyngeal insufficiency and sleep apnea. Fistula rates exhibit a wide variation by surgeon and type of repair. Some report, the Veau-Wardill-Kilner repair has a higher rate of fistula formation than the Von Langenbeck repair, which has a higher rate than the Furlow palatoplasty and intravelar veloplasty. Wide and bilateral clefts also suffer from higher fistula rates. It is 

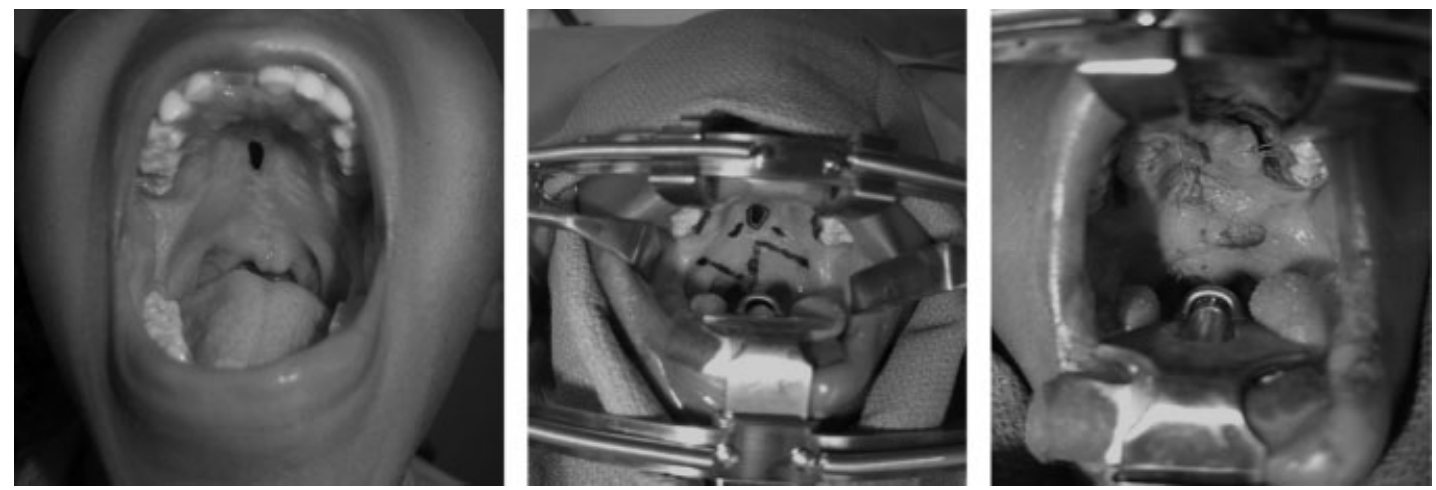

Fig. 3 Pre- and postoperative pictures status postfistula repair with a Furlow Z-plasty. Surgical markings are shown.

unclear whether timing of repair has an influence on fistula formation. ${ }^{33}$ Fistulas are usually diagnosed at an early age. Speech disturbances, including VPI, are often not evaluated until ages 5 to 6 when a child can cooperate with a speech exam. At that time, recommendations can be made for speech therapy, palatoplasty revision, or another compensatory procedure such as a pharyngoplasty or pharyngeal flap. Persistent VPI is present in 5 to $20 \%$ of patients, and likely depends on the surgeon's experience and the operative technique utilized. Primary palate repair appears to affect maxillary growth to a greater extent than repair of the secondary palate. Age at operation should be carefully considered, taking care to minimize growth disturbance of the midface while balancing the need for proper development of speech. Sleep apnea typically affects patients with Pierre Robin sequence to a greater extent than nonsyndromic cleft palate patients. Careful monitoring of these patients is needed to assess for symptoms of sleep apnea. In these patients, cleft palate repair may need to be delayed until airway compromise is treated with a tongue-lip adhesion or mandibular distraction. ${ }^{34}$ Overall, less favorable outcomes are seen in patients with velocardiofacial syndrome (VCFS). ${ }^{35}$ This is suspected to be due to several factors including poor muscular tone and the anatomic shape of the oropharynx.

Our understanding of cleft palates has come a long way since the early days of treatment. While closure of the defect is a primary goal, a thorough understanding of cleft palates and their associated problems will ensure that patients have successful long-term outcomes and adequate speech development. Optimal management of these children consists of a multidisciplinary team and a skilled surgeon.

\section{References}

1 Strong EB, Buckmiller LM. Management of the cleft palate. Facial Plast Surg Clin North Am 2001;9(1):15-25, vii

2 Vanderas AP. Incidence of cleft lip, cleft palate, and cleft lip and palate among races: a review. Cleft Palate J 1987;24(3): 216-225

3 Shprintzen RJ, Siegel-Sadewitz VL, Amato J, Goldberg RB. Anomalies associated with cleft lip, cleft palate, or both. Am J Med Genet $1985 ; 20(4): 585-595$
4 Fraser FC. The genetics of cleft lip and cleft palate. Am J Hum Genet 1970;22(3):336-352

5 Lorente C, Cordier S, Goujard J, et al; Occupational Exposure and Congenital Malformation Working Group. Tobacco and alcohol use during pregnancy and risk of oral clefts. Am J Public Health 2000;90(3):415-419

6 Källén B. Maternal drug use and infant cleft lip/palate with special reference to corticoids. Cleft Palate Craniofac J 2003;40 (6):624-628

7 Savitz DA, Schwingl PJ, Keels MA. Influence of paternal age, smoking, and alcohol consumption on congenital anomalies. Teratology 1991;44(4):429-440

8 Matthews MS, Cohen M, Viglione M, Brown AS. Prenatal counseling for cleft lip and palate. Plast Reconstr Surg 1998;101(1):1-5

9 Marks MW, Marks C. Cleft lip and palate. In: Fundamentals of Plastic Surgery. Philadelphia, PA: Saunders; 1997:156

10 Hopper RA, Cutting C, Grayson B. Cleft lip and palate. In: Thorne $\mathrm{CH}$ et al, eds. Grabb and Smith's Plastic Surgery. Philadelphia, PA: Lippincott, Williams \& Wilkins; 2007:201-225

11 Fisher DM, Sommerlad BC. Cleft lip, cleft palate, and velopharyngeal insufficiency. Plast Reconstr Surg 2011;128(4):342e-360e

12 Matsune S, Sando I, Takahashi H. Insertion of the tensor veli palatini muscle into the eustachian tube cartilage in cleft palate cases. Ann Otol Rhinol Laryngol 1991;100(6):439-446

13 Fraser FC. Workshop on embryology of cleft lip and cleft palate. Teratology 1968;1(3):353-358

14 Diah E, Lo LJ, Huang CS, Sudjatmiko G, Susanto I, Chen YR. Maxillary growth of adult patients with unoperated cleft: answers to the debates. J Plast Reconstr Aesthet Surg 2007;60(4):407-413

15 Sperber GH. Formation of the primary palate and palatogenesis: closure of the secondary palate. In: Wyszynski DF, ed. Cleft Lip and Palate: From Origin to Treatment. New York: Oxford University Press; 2002:5-24

16 Marazita ML, Mooney MP. Current concepts in the embryology and genetics of cleft lip and cleft palate. Clin Plast Surg 2004;31(2): 125-140

17 Yu JC, Hilton R, Magana RG. Pierre Robin sequence. Curr Ped Rev 2011;7(1):15-19

18 Gosain AK, Conley SF, Marks S, Larson DL. Submucous cleft palate: diagnostic methods and outcomes of surgical treatment. Plast Reconstr Surg 1996;97(7):1497-1509

19 McWilliams BJ. Submucous clefts of the palate: how likely are they to be symptomatic? Cleft Palate Craniofac J 1991;28(3):247-249, discussion 250-251

20 Veau V. Division Palatine. Paris: Masson \& Cie; 1931

21 Bessell A, Hooper L, Shaw WC, Reilly S, Reid J, Glenny AM. Feeding interventions for growth and development in infants with cleft lip, cleft palate or cleft lip and palate. Cochrane Database Syst Rev 2011;(2):CD003315 
22 Johns DF, Rohrich RJ, Awada M. Velopharyngeal incompetence: a guide for clinical evaluation. Plast Reconstr Surg 2003;112 (7):1890-1897, quiz 1898, 1982

23 Wyatt R, Sell D, Russell J, Harding A, Harland K, Albery E. Cleft palate speech dissected: a review of current knowledge and analysis. Br J Plast Surg 1996;49(3):143-149

24 Priester GH, Goorhuis-Brouwer SM. Speech and language development in toddlers with and without cleft palate. Int J Pediatr Otorhinolaryngol 2008;72(6):801-806

25 Takahashi H, Honjo I, Fujita A. Eustachian tube compliance in cleft palate-a preliminary study. Laryngoscope 1994;104(1 Pt 1): 83-86

26 van Aalst JA, Kolappa KK, Sadove M. MOC-PSSM CME article: Nonsyndromic cleft palate. Plast Reconstr Surg 2008;121(1, Suppl): $1-14$

27 Leow AM, Lo LJ. Palatoplasty: evolution and controversies. Chang Gung Med J 2008;31(4):335-345

28 Grayson BH, Maull D. Nasoalveolar molding for infants born with clefts of the lip, alveolus, and palate. Clin Plast Surg 2004; 31(2):149-158, vii
29 Shetye PR. Facial growth of adults with unoperated clefts. Clin Plast Surg 2004;31(2):361-371

30 Rohrich RJ, Love EJ, Byrd HS, Johns DF. Optimal timing of cleft palate closure. Plast Reconstr Surg 2000;106(2):413-421, quiz 422, discussion 423-425

31 Salyer KE, Sng KW, Sperry EE. Two-flap palatoplasty: 20-year experience and evolution of surgical technique. Plast Reconstr Surg 2006;118(1):193-204

32 Sommerlad BC. A technique for cleft palate repair. Plast Reconstr Surg 2003;112(6):1542-1548

33 Phua YS, de Chalain T. Incidence of oronasal fistulae and velopharyngeal insufficiency after cleft palate repair: an audit of 211 children born between 1990 and 2004. Cleft Palate Craniofac J 2008;45(2):172-178

34 Myer CM III, Reed JM, Cotton RT, Willging JP, Shott SR. Airway management in Pierre Robin sequence. Otolaryngol Head Neck Surg 1998;118(5):630-635

35 D’Antonio LL, Davio M, Zoller K, Punjabi A, Hardesty RA. Results of Furlow Z-plasty in patients with velocardiofacial syndrome. Plast Reconstr Surg 2001;107(4):1077-1079 